\title{
Efficacy and safety of pre-operative single dose parenteral tranexamic acid in moderately anaemic parturients undergoing caesarean section
}

\author{
Robin Medhi, Sonika Bawri*, Chaitra S. K., Mansur Ahmed, Asmita Mishra
}

Department of Obstetrics and Gynecology, Silchar Medical College and Hospital, Silchar, Assam, India

Received: 19 May 2017

Revised: 24 May 2017

Accepted: 20 June 2017

\section{*Correspondence:}

Dr. Sonika Bawri,

E-mail: sonikabawri@gmail.com

Copyright: (c) the author(s), publisher and licensee Medip Academy. This is an open-access article distributed under the terms of the Creative Commons Attribution Non-Commercial License, which permits unrestricted non-commercial use, distribution, and reproduction in any medium, provided the original work is properly cited.

\begin{abstract}
Background: Preoperative administration of Tranexamic acid (TXA) has been found to be effective in reducing the amount of blood loss following Caesarean section in low risk women. However, studies in high risk women such as women with anaemia, where blood loss needs to be minimised are scarce.

Methods: An experimental case control study was conducted with a total of 174 patients with moderate anaemia undergoing CS in a teaching hospital. Study group consisting of 87 patients received pre-operative TXA $1 \mathrm{~g}$ intravenously. Intra operative and up to 6hours postpartum blood loss was calculated in both the groups. Requirement of blood transfusions were noted. Data analysed using Graphpad Instat 3 statistical software.

Results: Present study showed statistically significant reduction in intraoperative and postoperative blood loss among patients who received TXA compared to control group. The blood loss from placental delivery till completion of the procedure was significantly lowered $(304.02 \mathrm{ml}$ vs $393.36 \mathrm{ml}$; p value $<0.0001)$. Postoperative blood loss (from end of the procedure up to $6 \mathrm{hrs}$ postpartum) was $62.57 \mathrm{ml}$ in comparison to $85.40 \mathrm{ml}$ in control group (p value $<0.0001$ ). The total blood loss from the placental delivery up to 6 hours postpartum was significantly reduced in study group $(366.59 \mathrm{ml}$ vs $478.76 \mathrm{ml}$; $\mathrm{p}$ value $<0.0001)$. There was significant reduction of blood transfusion in study group (RR: $0.20,95 \%$ CI, 0.045-0.887), without immediate adverse effect on mothers and new-borns.

Conclusions: Administration of TXA preoperatively causes significant decrease in blood loss and the need for blood transfusion in patients with moderate anaemia undergoing CS.
\end{abstract}

Keywords: Anaemia, Blood transfusion, Caesarean section, Tranexamic acid

\section{INTRODUCTION}

With changing times, Caesarean section (CS) has become a common mode of delivery worldwide. CS rate in India has doubled over the past decade $(8.5 \%$ in $2005-06$ to $17.2 \%$ in $2015-16) .{ }^{1}$ But delivery by CS is associated with higher maternal morbidity and mortality in comparison to normal vaginal delivery. The most important complication of CS is excessive blood loss during and after the operation which may lead to life threatening consequences. Average blood loss during CS varies from $800-1000 \mathrm{ml}^{2}$ Anaemic mothers undergoing CS are the most vulnerable group who may not even be able to bear the brunt of average blood loss during the procedure. In a country like India, with a prevalence of 45.7-52.1\% of anaemia among pregnant women and perennial shortage of blood for transfusion, it poses a great challenge to the obstetrician while treating anaemic mothers. ${ }^{1}$ Although various methods and uterotonic drugs have been in use to decrease the blood loss during CS, we are still in need of a cheaper and widely available drug to 
decrease the overall blood loss and need for blood transfusions.

Tranexamic acid(TXA) has been observed to decrease perioperative and postoperative bleeding and the need for blood transfusion in many surgeries. Many studies have reported advantages of TXA in CS in reducing blood loss among low risk patients. 3,4

However, very few studies have been conducted in high risk mothers with anaemia undergoing CS. ${ }^{5}$ Therefore, we have made an attempt to observe the efficacy of TXA in reducing intraoperative and postoperative blood loss and need for blood transfusion in moderately anaemic parturients undergoing CS.

\section{METHODS}

An experimental case control study was conducted between June 2015 to May 2016, in the Department of Obstetrics and Gynaecology of Silchar Medical College and Hospital, Silchar, which is the only tertiary care centre in South Assam. For this study, 174 pregnant women were enrolled as per inclusion and exclusion criteria. 87 women with singleton full term pregnancy with moderate anaemia (7-9.9g/dl) undergoing elective and emergency LSCS were included in study group and another 87 women with matching demographic profile as well as indications of CS were taken as control group.

Women with obstetric complications such as placenta praevia, abruptio placentae, allergy to TXA, patients with risk factors for venous thromboembolism and known cases of medical or surgical conditions involving liver and kidney were excluded from the study. An informed written consent was obtained from the willing participants. The study was approved by the Independent Ethics Committee of Silchar medical college and Hospital.

Patients assigned to study group received $1 \mathrm{gm}$ single dose of TXA intravenously over a period of 5mins, just before the skin incision. Oxytocin 10 units in $500 \mathrm{~mL}$ of
Ringer's lactate was given after delivery of the neonate in both the study and control group. Every LSCS was performed under spinal anaesthesia. The primary outcome was blood loss from delivery of the placenta till the completion of the operation and from the end of procedure up to 6 hours postpartum. Secondary outcomes were, need of blood transfusion following CS and the adverse effects of TXA.

Blood loss estimation commenced immediately after delivery of the placenta. Intraoperative blood loss was measured as the quantity of blood $(\mathrm{mL})=$ \{weight of used mops during operation $(\mathrm{g})$-weight of mops prior to surgery $(\mathrm{g}) /$ blood density $(1.05 \mathrm{~g} / \mathrm{mL})\}$ +volume of blood sucked in the suction container after placental delivery. In addition, the pads used after completion of caesarean section up to 6 hours postpartum were separately weighed to assess the blood loss postoperatively. Mops and pads were weighed using electronic weighing machine. The amount of blood loss prior to placental delivery was not included in our study as volume of amniotic fluid could have interfered in accurate estimation of blood loss.

Vital signs at the time of placental delivery and 6 hours post-partum were studied in both groups. Any side effects of TXA on the neonate (Apgar Score) and the mother (nausea, vomiting or diarrhoea) were noted. Laboratory analysis comprising complete blood count, urine routine and microscopy, liver and renal function tests were done before and $24 \mathrm{hrs}$ following delivery.

\section{Statistical analysis}

The data compiled were analysed with Graphpad Instat ${ }^{\circledR}$ 3 statistical software. The results were expressed as mean $\pm \mathrm{SD}$, mean difference or frequency. The qualitative variables were compared using the Chi-Square test. For quantitative variables, we used Student's t-test. A p value $<0.05$ was considered statistically significant.

\section{RESULTS}

A total of 174 participants were included in this study.

Table 1: Age, height, weight, BMI and indications of LSCS in both the groups.

\begin{tabular}{|c|c|c|c|}
\hline & Study group (mean \pm SD) $\mathbf{N}=\mathbf{8 7}$ & Control group (mean \pm SD) $\mathbf{N}=87$ & P value \\
\hline Age (years) & $22.78 \pm 2.63$ & $22.3 \pm 2.54$ & 0.2093 \\
\hline Height $(\mathrm{cm})$ & $153.02 \pm 2.552$ & $152.59 \pm 2.394$ & 0.2585 \\
\hline Weight (kg) & $57.862 \pm 3.296$ & $57.034 \pm 3.262$ & 0.0978 \\
\hline BMI & $24.717 \pm 1.535$ & $24.498 \pm 1.624$ & 0.3633 \\
\hline \multicolumn{4}{|l|}{ Indication of LSCS } \\
\hline CPD & 26 & 23 & 0.7360 \\
\hline Foetal distress & 31 & 33 & 0.8751 \\
\hline Oligohydramnios & 15 & 16 & 0.8430 \\
\hline Breech presentation & 9 & 11 & 0.8121 \\
\hline Face presentation & 4 & 1 & 0.3641 \\
\hline Transverse Lie & 2 & 3 & 0.6500 \\
\hline
\end{tabular}


Table 2: The primary outcome: blood loss during surgery and post postoperative period up to 6 hours.

\begin{tabular}{|c|c|c|c|}
\hline $\begin{array}{l}\text { Blood } \\
\text { Loss }(m L)\end{array}$ & $\begin{array}{l}\text { Study group } \\
\text { (Mean } \pm \text { SD) }\end{array}$ & $\begin{array}{l}\text { Control } \\
\text { group } \\
(\text { Mean } \pm \text { SD) }\end{array}$ & $\begin{array}{l}P \\
\text { value }\end{array}$ \\
\hline $\begin{array}{l}\text { Placental } \\
\text { delivery to } \\
\text { end of CS }\end{array}$ & $304.02 \pm 45.16$ & $393.36 \pm 72.31$ & $<0.0001$ \\
\hline $\begin{array}{l}\text { End of CS } \\
\text { to } 6 \text { hrs } \\
\text { Postpartum }\end{array}$ & $62.57 \pm 5.58$ & $85.40 \pm 10.54$ & $<0.0001$ \\
\hline $\begin{array}{l}\text { Placental } \\
\text { Delivery to } \\
\text { 6hrs } \\
\text { postpartum }\end{array}$ & $366.59 \pm 44.29$ & $478.76 \pm 73.45$ & $<0.0001$ \\
\hline
\end{tabular}

All the participants had moderate anaemia (7-9.9g/dl). Both the study and control group were matched in terms of demographic profile and indications of CS. Patients' characteristics including indication of $\mathrm{CS}$ are shown in Table 1. No statistically significant differences were observed between the two groups.
CS were conducted by 3 of our qualified faculty members with minimum of 8 years' experience with assistance from residents of the institution.

The intraoperative blood loss i.e. from placental delivery up to the completion of the operation was significantly lower in study group $(304.02 \mathrm{ml}$ vs $393.36 \mathrm{ml}$; p value $<0.0001)$. it was also observed that the blood loss from completion of the procedure to 6 hours postpartum were significantly lower in study group in comparison to control group $(62.57 \mathrm{ml}$ vs $85.40 \mathrm{ml}$; p value $<0.0001)$.

Overall, significantly reduced blood loss was observed from placental delivery up to 6hours postpartum in study group compared to control group $(366.59 \mathrm{ml}$ vs $478.76 \mathrm{ml}$; $\mathrm{p}$ value $<0.0001)$. The reduced blood loss was reflected in the haemoglobin levels of the study population.

The estimated postoperative haemoglobin level, 24hrs after delivery was significantly lower in the control group with preoperative value of $8.703 \mathrm{~g} / \mathrm{dl}$ and postoperative level of $7.625 \mathrm{~g} / \mathrm{dl}(\mathrm{p}<0.0001)$ as compared to study group with preoperative value of $8.716 \mathrm{~g} / \mathrm{dl}$ and postoperative level of $7.932 \mathrm{~g} / \mathrm{dl}(\mathrm{p}<0.0001)$ as shown in Table 3.

Table 3: The difference in the $\mathrm{Hb}(\mathrm{g} / \mathrm{dl})$-post operatively between study and control group.

\begin{tabular}{|c|c|c|c|c|c|c|}
\hline \multicolumn{3}{|c|}{ Study group } & \multicolumn{4}{|c|}{ Control group } \\
\hline Hb (g/dl) & Mean & SD & Mean & SD & Mean difference & $P$ value \\
\hline Before delivery & 8.716 & 0.538 & 8.703 & 0.536 & 0.013 & 0.8769 \\
\hline 6hrs after delivery & 7.932 & 0.596 & 7.625 & 0.552 & 0.307 & 0.0006 \\
\hline Difference & 0.779 & 0.254 & 1.110 & 0.269 & -0.331 & $<0.0001$ \\
\hline
\end{tabular}

Table 4: Comparison of the need for blood transfusion in both the groups.

\begin{tabular}{|ll|llll}
$\begin{array}{l}\text { Blood } \\
\text { transfusion }\end{array}$ & $\begin{array}{l}\text { Study group } \\
\text { (no. of cases) }\end{array}$ & $\begin{array}{l}\text { Control group } \\
\text { (no. of cases) }\end{array}$ & P value & Relative risk & $95 \%$ CI \\
\hline Required & 2 & 10 & 0.0362 & 0.2000 & $0.045-0.887$ \\
\hline
\end{tabular}

Study group showed a decrease of $0.779 \mathrm{~g} / \mathrm{dl}$ compared to preoperative values while control group showed a deficit of $1.11 \mathrm{~g} / \mathrm{dl}$. Blood transfusion was needed in 2 patients in study group compared to 10 patients in control group ( $\mathrm{p}$ 0.0362 ).

The relative risk of having blood transfusions in the study group (2/87) compared to control group (10/87) was 0.20 (95\% CI, 0.045-0.887) shown in Table 4.
Table 5 shows $1 \mathrm{~min}$ and $5 \mathrm{~min}$ Apgar scores of the babies born. There was no significant difference between study and control group ( 0.6607 and $\mathrm{p} 0.6128$ ), indicating that TXA had no significant adverse effect in relation to foetal outcome. Maternal TXA induced adverse effects did not differ between the 2 groups (Table 6). No incidence of thromboembolic event or mortality emerged in any of the participants.

Table 5: Comparison of apgar score in both the groups.

\begin{tabular}{|lllllll|}
\hline A pgar Score & Study Group & \multicolumn{2}{c}{ Control Group } & \multicolumn{2}{c|}{ P value } \\
\hline & Mean & SD & Mean & SD & Mean difference & 0.6607 \\
\hline $1 \mathrm{~min}$ & 7.151 & 0.727 & 7.103 & 0.699 & 0.0477 & 0.6128 \\
\hline
\end{tabular}


Table 6: Comparison of maternal adverse effects in both the groups.

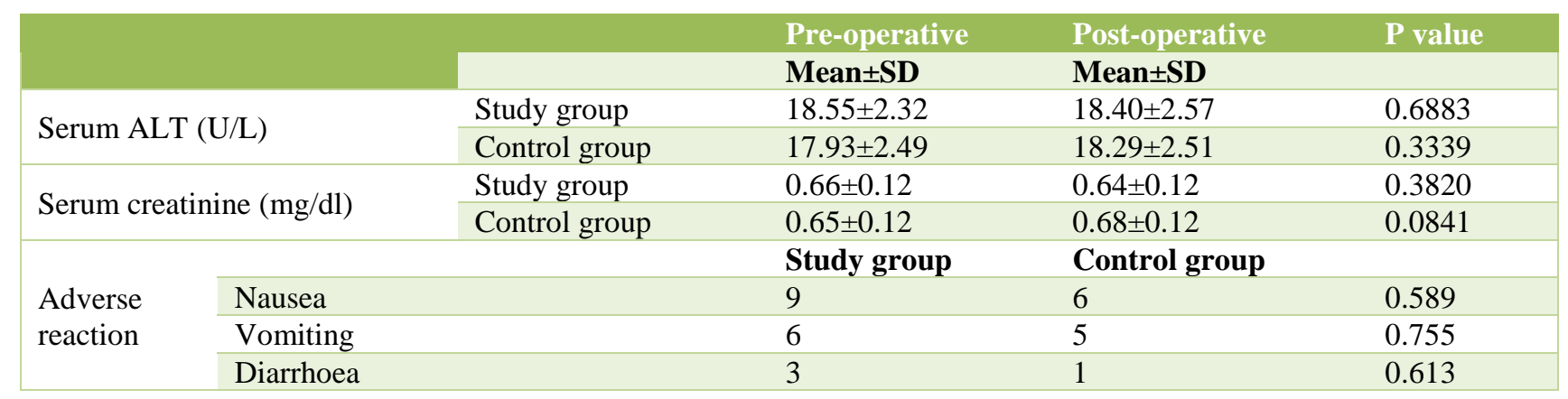

\section{DISCUSSION}

In developing countries like India, with high prevalence of anaemia among pregnant women, blood loss during delivery particularly during CS is a major concern. The overall prevalence of anaemia among pregnant women is reported to be $45.7 \%-52.1 \%$ out of which majority are moderately anaemic. ${ }^{1}$ Various uterotonics in the form of intravenous oxytocin, ergometrine, oxytocin-ergometrine fixed dose, or prostaglandin drugs are recommended for prevention of postpartum haemorrhage. Still we are in need of a cheaper and effective drug to further decrease the blood loss and the need for blood transfusion during these procedures. TXA, an antifibrinolytic seems to be a promising drug.

TXA is an antifibrinolytic agent which helps the blood clotting system in reducing bleeding. It is a synthetic analogue of amino acid lysine and competitively blocks the lysine-binding site of plasminogen to fibrin.

During placental delivery, rapid degradation of fibrinogen to fibrin and an increase in the activation of plasminogen activators occurs and also the increase in fibrin degradation products due to activation of the fibrinolytic system. This activation may last up to 6-10 hours postpartum, which may cause increased postpartum bleeding.

The antifibrinolytic effect of TXA, administered in the preoperative period could make it an effective adjunct to other drugs currently used to decrease the blood loss. ${ }^{6}$ In recent years, TXA has been used to prevent or decrease intraoperative and postoperative blood loss in various surgeries. $^{7-9}$

In our study, we found that TXA significantly reduced the blood loss from placental delivery up to completion of CS $(304.02 \mathrm{ml}$ vs $393.36 \mathrm{ml}$; p value $<0.0001$ i.e. $89.34 \mathrm{ml}$ less than control group). It has shown to significantly reduce the postpartum blood loss from the end of procedure till 6 hours postpartum $(62.57 \mathrm{ml}$ vs $85.40 \mathrm{ml}$; p value $<0.0001$ i.e. $22.83 \mathrm{ml}$ less than control group). Overall reduction of blood loss from placental delivery up to 6 hours postpartum was also observed to be significant in study group $(366.59 \mathrm{ml}$ vs $478.76 \mathrm{ml}$; $\mathrm{p}$ value: $<0.0001$ i.e. $112.17 \mathrm{ml}$ less than control group). Our observations correlated with the findings of several studies conducted..$^{3-5}$ We could discover one study done previously on anaemic women undergoing $\mathrm{CS}^{5}$ However, our study has been conducted to investigate the blood loss up to 6 hours postpartum as compared to 2 hours in the aforementioned study. The decrease in postpartum blood loss up to 6 hours indicates the action of TXA may last up to 6 hours postpartum.

The reduced blood loss in the study group correlated with the haemoglobin levels. There was a significant decrease in haemoglobin levels, 24hours postoperatively in control group (preoperative mean value of $8.703 \mathrm{~g} / \mathrm{dl}$ and postoperative level of $7.625 \mathrm{~g} / \mathrm{dl}$, deficit of $1.11 \mathrm{~g} / \mathrm{dl}$, $\mathrm{p}<0.0001$ ) as compared to study group (preoperative mean value of $8.716 \mathrm{~g} / \mathrm{dl}$ and postoperative level of $7.932 \mathrm{~g} / \mathrm{dl}$, deficit of $0.779 \mathrm{~g} / \mathrm{dl}, \mathrm{p}<0.0001)$. It denotes the evidence of decreased blood loss in quantitative terms. However, it does not reflect the exact reduction of blood loss as more patients had blood transfusion in control group.

The present study showed a significant reduction in requirement of blood transfusion with TXA ( 2 patients in study group as compared to 10 patients in control group, $\mathrm{p}=0.0362$, RR- 0.20, 95\% CI: 0.045-0.887). Similar results were reported in other studies. ${ }^{3-5}$

In the present study, TXA did not have any adverse effects on the Apgar score of the baby. There was no increased incidence of side effects in patients like nausea, vomiting and diarrhoea in the TXA group compared to control group. Although venous thromboembolism is a potential side effect of TXA, our study did not have such incidences. The reason may be because the participants were of younger age, non-smokers, of Asian ethnicity and smaller size of the study population. ${ }^{10}$

Present study suggests that TXA can be used effectively and safely in moderately anaemic women undergoing CS, without any major immediate adverse effects on the mother or the neonate. 


\section{CONCLUSION}

Preoperative intravenous 1gm TXA administration in moderately anaemic women undergoing CS significantly reduces both the intraoperative and postoperative blood loss without any major and immediate adverse maternal and neonatal complications. TXA also decreases the need of blood transfusion and thereby prevents hazards of blood transfusion.

Funding: No funding sources

Conflict of interest: None declared

Ethical approval: The study was approved by the Institutional Ethics Committee

\section{REFERENCES}

1. NFHS-4. 2015-16. Factsheet: Available at www.rchiips.org/nfhs.

2. Healy TEJ, Knight PR. Obstetric Anaesthesia. Wilie and Churchill Davidson's A Practice of Anaesthesia. 7th edition. Churchill-Davidson; 2003:934.

3. Ramani B, Nayak L. Intravenous 1gram tranexamic acid for prevention of blood loss and blood transfusion during caesarean section: a randomised case control study. Int J Reprod Contracept Obstet Gynecol. 2014;3:366-9.

4. Wang HY, Hong SK, Duan Y, Yin HM. Tranexamic acid and blood loss during and after caesarean section: a meta-analysis. J Perinatol. 2015;35(10):818-25.
5. Goswami U, Sarangi S, Gupta S, Babbar S. Comparative evaluation of two doses of tranexamic acid used prophylactically in anemic parturients for lower segment caesarean section: A double-blind randomised case control prospective trial. Saudi J Anaesth. 2013;7:427-31.

6. Novikova N, Hofmeyr GJ, Cluver C. Tranexamic acid for preventing postpartum haemorrhage. Cochrane Database Syst Rev. 2015;(6):CD007872.

7. Rajesparan K, Biant LC, Ahmad M, Field RE. The effect of an intravenous bolus of tranexamic acid on blood loss in total hip replacement. J Bone Joint Surg Br. 2009;91(6):776-83.

8. Neilipovitz DT. Tranexamic acid for major spinal surgery. Eur Spine J. 2004;13(Suppl 1):S62-5.

9. Benoni G. Tranexamic acid reduces the blood loss in knee arthroplasty- if it's administered at the right time. Lakartidningen. 1999;96(24):2967-9.

10. Cheuk BL, Cheung GC, Cheng SW. Epidemiology of venous thromboembolism in a Chinese population. Br J Surg. 2004;91:424-8.

Cite this article as: Medhi R, Bawri S, Chaitra SK, Ahmed M, Mishra A. Efficacy and safety of preoperative single dose parenteral tranexamic acid in moderately anaemic parturients undergoing caesarean section. Int J Reprod Contracept Obstet Gynecol 2017;6:3423-7. 